\title{
Rothia terrae sp. nov. isolated from soil in Taiwan
}

Correspondence

Wen-Ming Chen

p62365@ms28.hinet.net

\author{
Yi-Ju Chou, ${ }^{1}$ Jui-Hsing Chou, ${ }^{2}$ Kuan-Yin Lin, ${ }^{1}$ Mei-Chun Lin, ${ }^{1}$ \\ Yu-Hong Wei, ${ }^{3}$ A. B. Arun, ${ }^{2}$ Chiu-Chung Young ${ }^{2}$ and Wen-Ming Chen ${ }^{1}$
}

\author{
${ }^{1}$ Laboratory of Microbiology, Department of Seafood Science, National Kaohsiung Marine \\ University, No. 142 Hai-Chuan Road, Nan-Tzu, Kaohsiung City 811, Taiwan, ROC \\ ${ }^{2}$ Department of Soil and Environmental Sciences, College of Agriculture and Natural Resources, \\ National Chung Hsing University, Taichung, Taiwan, ROC \\ ${ }^{3}$ Graduate School of Biotechnology and Bioinformatics, Yuan-Ze University, Chung-Li, \\ Taoyuan 320, Taiwan, ROC
}

\begin{abstract}
A cream-white-coloured, aerobic, Gram-positive, ovoid to spherical-shaped bacterial strain, designated $\mathrm{L}-143^{\top}$, was isolated from soil in Taiwan. The highest $16 \mathrm{~S}$ rRNA gene sequence similarities of strain L-143 ${ }^{\top}$ (98.3-95.8\%) were with members of the genus Rothia.

Chemotaxonomic and phenotypic properties of this organism were consistent with its classification in the genus Rothia. The novel isolate was distinguished from all Rothia species by several phenotypic characteristics. The peptidoglycan type was $A 3 \alpha$, containing lysine, glutamic acid and alanine. The isolate contained MK-7 as the major component of the quinone system. The predominant polar lipid consisted of phosphatidylglycerol and diphosphatidylglycerol, with some unknown phospho- and glycolipids as minor components. The major fatty acids were anteiso-15:0 (57.3\%), anteiso-17:0 (17.0\%) and 16:0 (9.3\%). The $\mathrm{G}+\mathrm{C}$ content of the genomic DNA was 56.1 mol\%. Hence, genotypic, chemotaxonomic and phenotypic data demonstrate that strain $L-143^{\top}$ should be classified as a novel species in the genus Rothia, for which the name Rothia terrae sp. nov. is proposed. The type strain is $L-143^{\top}$ (=BCRC $17588^{\top}=$ LMG $23708^{\top}$ ).
\end{abstract}

The genus Rothia was proposed by Georg \& Brown (1967). Historically, this taxon was classified in the family Actinomycetaceae because of similarities in morphological characteristics (Schaal, 1992). Stackebrandt et al. (1997) further amended and transferred the genus to the Micrococcaceae based on phylogenetic and other analyses. Currently, Rothia encompasses five species with validly published names: Rothia aeria, Rothia amarae, Rothia dentocariosa, Rothia mucilaginosa and Rothia nasimurium. All five reported Rothia species are Gram-positive and form non-motile coccoid cells. $R$. dentocariosa and $R$. mucilaginosa were isolated from the human oral cavity and pharynx (Schaal, 1992; Collins et al., 2000), respectively. $R$. dentocariosa has been identified to be an opportunistic pathogen causing septicaemia, endocarditis and other serious infections (Schafer et al., 1979; Pape et al., 1979; Minato \& Abiko, 1984; Pers et al., 1987; Schiff \& Kaplan, 1987). R. nasimurium was isolated from the nose of a healthy mouse (Collins et al., 2000) while R. amarae was

The GenBank/EMBL/DDBJ accession number for the $16 \mathrm{~S}$ rRNA gene sequence of the strain L-143 ${ }^{\top}$ is DQ822568.

A supplementary table of fatty acid composition data and a supplementary figure showing the polar lipid profile of strain $L-143^{\top}$ are available with the online version of this paper. isolated from sludge of a foul water sewer (Fan et al., 2002). $R$. aeria was isolated from air samples collected from the Russian space laboratory Mir (Li et al., 2004).

In the course of a study aiming to isolate actinomycetes from subtropical fields, strain L-143 ${ }^{\mathrm{T}}$ was isolated from a soil sample collected from Tainan County, Taiwan. This organism was isolated on an HV agar plate (Hayakawa \& Nonomura, 1987) that had been incubated at $30{ }^{\circ} \mathrm{C}$ for 3 days following inoculation with a suspension of a soil sample. Strain $\mathrm{L}-143^{\mathrm{T}}$ was further maintained on nutrient agar (BD Difco). The strain was preserved at $-80{ }^{\circ} \mathrm{C}$ in nutrient broth (BD Difco) with $20 \%$ (v/v) glycerol or by lyophilization. The organism was the subject of a polyphasic taxonomic study which showed that it belonged to a new species of Rothia. The name proposed for this taxon is Rothia terrae sp. nov.

The morphology of the bacterial cells was observed during the lag, exponential and stationary phases of growth under a phase-contrast microscope. The motility of the cells was tested by a hanging drop method. Flagellum staining was performed by using the Spot Test Flagella Stain (BD Difco). The Gram reaction was performed using the Gram Stain Set (BD Difco) and the Ryu non-staining KOH method (Powers, 1995). Accumulation of poly- $\beta$-hydroxybutyrate granules 
was observed under a light microscope after staining cells with Sudan black. The optimum $\mathrm{pH}$ range for growth was examined in nutrient broth using appropriate biological buffers (pH 4-10 at intervals of $1.0 \mathrm{pH}$ unit) (Chung et al., 1995). $\mathrm{pH}$ was adjusted prior to sterilization; post-sterilization controls revealed that only minor changes in $\mathrm{pH}$ values had occurred. The requirement for $\mathrm{NaCl}$ was determined using nutrient broth containing $0,0.5$ and $1.0-10.0 \%(\mathrm{w} / \mathrm{v})$ $\mathrm{NaCl}$ (at $1.0 \%$ intervals). The temperature range for growth $\left(4,10,15,20,25,30,35,40\right.$ and $\left.45{ }^{\circ} \mathrm{C}\right)$ was examined in nutrient broth adjusted to $\mathrm{pH} 7$. Growth was examined by measuring the turbidity $\left(\mathrm{OD}_{600}\right)$ of cultures grown at various $\mathrm{pH}$ values, $\mathrm{NaCl}$ concentrations and temperatures. Anaerobic cultivation was performed on nutrient agar using the Oxoid AnaeroGen system.

Strain L-143 ${ }^{\mathrm{T}}$ grew well aerobically in complex media, such as trypticase soy, nutrient and Luria-Bertani media. Strain $\mathrm{L}-143^{\mathrm{T}}$ could grow under anaerobic conditions, but the growth was poor.

Extraction of genomic DNA, PCR amplification and sequencing of the $16 \mathrm{~S}$ rRNA gene were carried out as described by Chen et al. (2001). Sequence reaction fragments were separated using a DNA sequencer (ABI PRISM 310; Applied Biosystems) and sequences were assembled by using the Fragment Assembly System program from the Wisconsin Package 9.1 (Genetics Computer Group, Madison, WI, USA). The resultant sequence was compared with available 16S rRNA gene sequences from the Ribosomal Database Project and GenBank databases. The multiple-sequence alignment including strain $\mathrm{L}-143^{\mathrm{T}}$ and its closest relatives was performed using BioEdit software (Hall, 1999) and MEGA version 3.1 (Kumar et al., 2004). Phylogenetic trees were inferred using the maximum-likelihood (Felsenstein, 1981), maximum-parsimony (Kluge \& Farris, 1969) and neighbour-joining (Saitou \& Nei, 1987) tree-making algorithms. An evolutionary distance matrix was generated for the neighbour-joining algorithm using the Jukes \& Cantor (1969) distance model and bootstrap analysis (1000 resamplings).

The nearly complete $16 \mathrm{~S}$ rRNA gene sequence (1436 nt) of strain $\mathrm{L}-143^{\mathrm{T}}$ was obtained. A comparison of the sequence with those of representatives of the genera classified in the family Micrococcaceae of the Actinobacteria showed that the organism fell within the evolutionary radiation occupied by the genus Rothia (Fig. 1). In the tree based on the neighbour-joining algorithm, strain $\mathrm{L}-143^{\mathrm{T}}$ formed a coherent cluster with $R$. nasimurium CCUG $35957^{\mathrm{T}}$ and R. amarae JCM $11375^{\mathrm{T}}$; the branching order was supported further by higher bootstrap values. A similar tree topology was also obtained with the phylogenetic trees generated using maximum-parsimony and maximum-likelihood algorithms (data not shown). Sequence similarity calculations based on pairwise alignment obtained using the EzTaxon database (Chun et al., 2007) showed the highest degree of similarity to $R$. nasimurium CCUG $35957^{\mathrm{T}}$ and $R$. amarae JCM $11375^{\mathrm{T}}$, sharing a $16 \mathrm{~S}$ rRNA gene sequence similarity of 98.3 and $97.6 \%$, respectively. Strain L-143 shared much lower 16S rRNA gene sequence similarity with other type strains: $R$. dentocariosa $(96.0 \%), R$. aeria (96.0\%) and R. mucilaginosa (95.8\%).

DNA-DNA hybridization experiments were performed in triplicate with photobiotin-labelled probes as described by Ezaki et al. (1989). Additionally, reciprocal analysis was

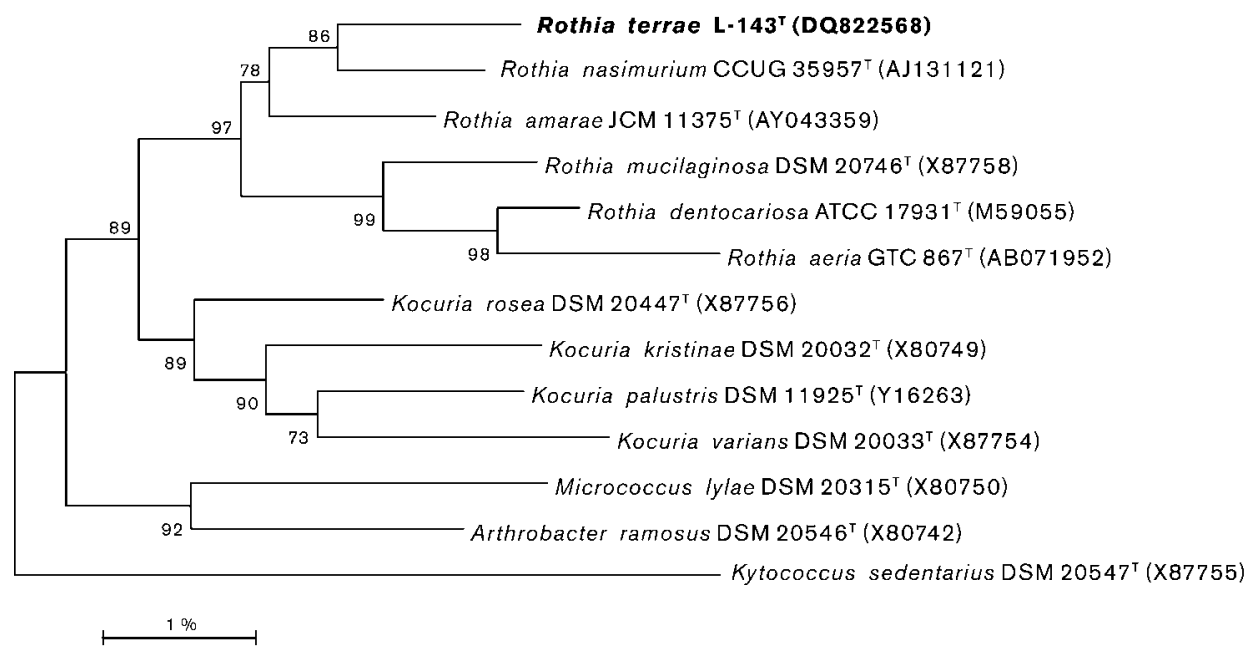

Fig. 1. Phylogenetic tree based on the $16 \mathrm{~S}$ rRNA gene sequences of strain $L-143^{\top}$, other Rothia species and related taxa. Sequences were retrieved from the EMBL database (accession numbers are given in parentheses). Distances were calculated and clustering with the neighbour-joining method was performed by using the software package MEGA version 3.1. Numbers at nodes are bootstrap values (\%) based on 1000 resampled datasets; only values above $50 \%$ are given. Bar, $1 \%$ sequence dissimilarity per nucleotide position. The sequence of Kytococcus sedentarius was used as outgroup. 
carried out to avoid any inconsistency during DNA binding. DNA-DNA hybridization results indicated low levels of relatedness between strain $\mathrm{L}-143^{\mathrm{T}}$ and its closest phylogenetic neighbours $R$. nasimurium CCUG $35957^{\mathrm{T}}$ $[21.0 \pm 2.8$ and $12.7 \pm 1.1 \%$ (reciprocal)] and $R$. amarae JCM $11375^{\mathrm{T}} \quad[15.3 \pm 5.0$ and $10.7 \pm 2.1 \%$ (reciprocal)]. These values are clearly below the $70 \%$ cut-off point recommended for the assignment of strains to the same genomic species (Wayne et al., 1987), indicating that strain $\mathrm{L}-143^{\mathrm{T}}$ warrants novel species status in the genus Rothia.

The DNA G + C content of strain $\mathrm{L}-143^{\mathrm{T}}$ was determined in triplicate as described by Mesbah et al. (1989) and was found to be $56.1 \pm 0.5 \mathrm{~mol} \%$ (Table 1 ).

Chemosystematic studies were carried out to establish whether strain $\mathrm{L}-143^{\mathrm{T}}$ had a chemical profile consistent with its assignment to the genus Rothia. Biomass for the fatty acid and chemical studies was grown in shake flasks of nutrient agar for 3 days at $30{ }^{\circ} \mathrm{C}$. Fatty acid methyl esters were prepared, separated and identified according to the instructions of the Microbial Identification System (MIDI; Microbial ID) (Sasser, 1990). Polar lipids were extracted and analysed by two-dimensional TLC according to Embley \& Wait (1994). Purified cell-wall preparations were obtained by the method of Schleifer \& Kandler (1972). The amino acids in peptidoglycan hydrolysates were analysed by TLC as outlined in Schleifer (1985) and the composition of amino acids was determined by HPLC using the Pico Tag system (Waters Associates). Menaquinones were extracted and analysed by HPLC as described by Collins (1994). Strain L-143 ${ }^{\mathrm{T}}$ shared chemotaxonomic characteristics consistent with the genus Rothia. The major cellular fatty acid composition of strain L-143 ${ }^{\mathrm{T}}$ showed the presence of anteiso-15:0 (57.3\%), anteiso$17: 0(17.0 \%)$ and 16:0 (9.3\%) fatty acids. Details of the cellular fatty acid composition with other closely related Rothia species are presented in Table S1 (available with the online version of the paper). In general, all these organisms had similar whole-cell fatty acid profiles (Collins et al., 2000; Fan et al., 2002; Li et al., 2004). The predominant

Table 1. Phenotypic characteristics separating isolate $L-143^{\top}$ from representatives of closely related Rothia species

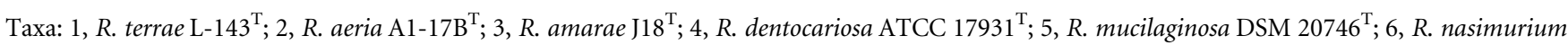
CCUG $35957^{\mathrm{T}}$. Data for $R$. amarae $\mathrm{J} 18^{\mathrm{T}}$ and $R$. nasimurium CCUG $35957^{\mathrm{T}}$ were obtained in this study, but DNA G $+\mathrm{C}$ content and major menaquinone data were from Collins et al. (2000) and Fan et al. (2002). Data for $R$. aeria $\mathrm{A} 1-17 \mathrm{~B}^{\mathrm{T}}$, R. dentocariosa ATCC $17931^{\mathrm{T}}$ and $R$. mucilaginosa DSM $20746^{\mathrm{T}}$ were from Li et al. (2004). +, Positive; -, negative; (+), weak reaction; ND, not determined.

\begin{tabular}{|c|c|c|c|c|c|c|}
\hline Character & 1 & 2 & 3 & 4 & 5 & 6 \\
\hline Catalase & + & + & + & + & - & + \\
\hline Trypsin & - & $\mathrm{ND}$ & - & - & - & + \\
\hline Valine arylamidase & - & $\mathrm{ND}$ & - & - & - & + \\
\hline Alkaline phosphatase & + & - & - & - & + & - \\
\hline$\beta$-Glucosidase & + & + & - & + & + & - \\
\hline Voges-Proskauer test & + & ND & + & + & + & - \\
\hline \multicolumn{7}{|l|}{ Acid production from: } \\
\hline Lactose & + & - & - & - & - & + \\
\hline Ribose & - & - & + & + & - & - \\
\hline \multicolumn{7}{|l|}{ Oxidation of (Biolog GP2): } \\
\hline 3-Methylglucose & + & + & - & - & + & + \\
\hline Methyl- $\alpha$-D-glucoside & - & + & + & - & - & - \\
\hline Methyl- $\beta$-D-glucoside & - & + & + & - & + & + \\
\hline D-Psicose & + & + & $(+)$ & - & - & + \\
\hline Salicin & - & + & - & - & + & - \\
\hline L-Malic acid & - & - & - & + & - & - \\
\hline$\alpha$-Hydroxybutyric acid & - & + & - & + & - & - \\
\hline Pyruvic acid & - & - & - & $(+)$ & + & + \\
\hline Succinic acid & - & - & - & + & - & - \\
\hline L-Lactic acid & + & + & $(+)$ & + & - & - \\
\hline Methylpyruvate & + & - & - & + & + & - \\
\hline Monomethyl succinate & - & - & - & $(+)$ & - & - \\
\hline 2,3-Butanediol & - & - & - & + & + & + \\
\hline Glycerol & + & + & + & + & - & + \\
\hline DL- $\alpha$-Glycerol phosphate & - & - & - & - & + & - \\
\hline Major menaquinone(s) & MK-7 & MK-7 & MK-6 $\left(\mathrm{H}_{2}\right)$, MK-7 & MK-7 & MK-7 & ND \\
\hline DNA G + C content $(\mathrm{mol} \%)$ & 56.1 & 57.8 & 54.5 & ND & $56-61$ & 56 \\
\hline
\end{tabular}


polar lipids of strain L-143 $3^{\mathrm{T}}$ were phosphatidylglycerol and diphosphatidylglycerol, with some unknown phospho- and glycolipids as minor components (Fig. S1, available with the online version of the paper). The TLC analysis indicated that strain $\mathrm{L}-143^{\mathrm{T}}$ lacks diaminopimelic acid in the cell wall. Further HPLC analysis of the peptidoglycan showed the presence of amino acids glutamic acid, alanine and lysine in a molar ratio of $1: 3: 1$. These results confirmed that the peptidoglycan type of strain $\mathrm{L}-143^{\mathrm{T}}$ was A3 $\alpha$ (Schleifer \& Kandler, 1972), which is also consistent with $R$. aeria (Li et al., 2004) and $R$. amarae (Fan et al., 2002). The predominant menaquinone of strain L-143 was MK-7 (Table 1).

Strain L-143 ${ }^{\mathrm{T}}$ was examined for a broad range of phenotypic properties. Catalase, oxidase, acid production from carbohydrate, triple-sugar iron agar test, Voges-Proskauer test, motility test and hydrolysis of starch, casein, Tween 20, Tween 40, Tween 60 and Tween 80 were determined using standard methods (Gerhardt et al., 1994; Lanyi, 1987; MacFaddin, 2000). Additional biochemical tests were performed by using commercially available API Coryne and API ZYM (bioMérieux), and Biolog GP2 microtest systems according to the methods outlined by the manufacturers. Sensitivity of strain $\mathrm{L}-143^{\mathrm{T}}$ to different antibiotics was analysed by the disc diffusion method on nutrient agar plates. The following antibiotic discs were used: ampicillin $(10 \mu \mathrm{g})$, chloramphenicol $(30 \mu \mathrm{g})$, erythromycin $(15 \mu \mathrm{g})$, gentamicin $(10 \mu \mathrm{g})$, kanamycin $(30 \mu \mathrm{g})$, nalidixic acid $(30 \mu \mathrm{g})$, novobiocin $(30 \mu \mathrm{g})$, rifampicin $(5 \mu \mathrm{g})$, penicillin $\mathrm{G}(10 \mathrm{U})$, streptomycin $(10 \mu \mathrm{g})$ and tetracycline $(30 \mu \mathrm{g})$. The effect of antibiotics on cell growth was assessed after 3 days incubation at $30{ }^{\circ} \mathrm{C}$.

Detailed results of the phenotypic study are provided in Table 1 and in the species description below. The phenotypic properties of strain $\mathrm{L}-143^{\mathrm{T}}$ were similar to those reported for other species in the genus Rothia, such as positive results for nitrate reduction, aesculin hydrolysis and acid production from D-glucose, sucrose and maltose, but negative results for urease, and acid production from xylose and D-mannitol. These characteristics strongly support the inclusion of strain $\mathrm{L}-143^{\mathrm{T}}$ in the genus Rothia. However, a few characteristics that are unique to strain $\mathrm{L}-143^{\mathrm{T}}$ differentiate it from other type strains of Rothia species (Table 1).

Phenotypic, chemotaxonomic and phylogenetic data support the description of strain $\mathrm{L}-143^{\mathrm{T}}$ as a novel species in the genus Rothia. The name Rothia terrae sp. nov. is proposed for this taxon.

\section{Description of Rothia terrae sp. nov.}

Rothia terrae (ter'rae. L. gen. n. terrae, of the earth, referring to the organism being isolated from soil).

Strain L-143 ${ }^{\mathrm{T}}$ forms visible cream-white colonies, circular and convex in shape with entire edges. Cells are Gram-positive, non-spore-forming, non-motile, ovoid to spherical, $0.5-1.0 \mu \mathrm{m}$ in width and $0.5-1.5 \mu \mathrm{m}$ in length. Cells occur either singly or in pairs or tetrads. Nonpigmented. Facultatively anaerobic and catalase-positive. Grows at $15-40{ }^{\circ} \mathrm{C}$, in the presence of $0-7.0 \% \mathrm{NaCl}$ and at pH 5-10. Optimum growth occurs at $35{ }^{\circ} \mathrm{C}$, with $0-0.5 \%$ $\mathrm{NaCl}$ and at $\mathrm{pH}$ 7.0-8.0. No accumulation of poly- $\beta$ hydroxybutyrate granules. Acid is produced from fructose, mannose, glycerol and trehalose. Acid is not produced from adonitol or salicin. Voges-Proskauer-positive. Starch, casein, Tween 20, Tween 40, Tween 60 and Tween 80 are not hydrolysed. Hydrogen sulfide production is not detected on triple-sugar iron agar. Positive (API Coryne) for nitrate reduction, pyrazinamidase, alkaline phosphatase, $\beta$-galactosidase, $\alpha$-glucosidase, aesculin hydrolysis, gelatin hydrolysis and acid production from D-glucose, Dmaltose, D-lactose and D-sucrose. Negative (API Coryne) for pyrrolidonyl arylamidase, $\beta$-glucuronidase, $N$-acetyl- $\beta$ glucosaminidase, urease and acid production from D-ribose, D-xylose, D-mannitol and glycogen. Positive (API ZYM) for alkaline phosphatase, C4 esterase, C8 lipase, leucine arylamidase, naphthol-AS-BI-phosphohydrolase, $\beta$-galactosidase, $\alpha$-glucosidase and $\beta$-glucosidase. Negative (API ZYM) for C14 lipase, valine arylamidase, cysteine arylamidase, trypsin, $\alpha$-chymotrypsin, acid phosphatase, $\alpha$-galactosidase, $\beta$-glucuronidase, $N$-acetyl- $\beta$-glucosaminidase, $\alpha$ mannosidase and $\alpha$-fucosidase. The following carbon sources are utilized (Biolog GP2 system): dextrin, glycogen, D-fructose, $\alpha$-D-glucose, maltose, D-mannose, 3-methyl-Dglucose, D-psicose, sucrose, D-trehalose, turanose, D-lactic acid methyl ester, L-lactic acid, pyruvic acid methyl ester, Lserine and glycerol. The following carbon sources are not utilized (Biolog GP2 system): $\alpha$-cyclodextrin, $\beta$-cyclodextrin, inulin, mannan, Tween 40 , Tween $80, N$-acetyl-Dglucosamine, $N$-acetyl- $\beta$-D-mannosamine, amygdalin, L-arabinose, D-arabitol, arbutin, D-cellobiose, L-fucose, Dgalactose, D-galacturonic acid, gentiobiose, $m$-inositol, $\alpha$-Dlactose, lactulose, maltotriose, D-mannitol, D-melezitose, D-melibiose, $\alpha$-methyl-D-galactoside, $\beta$-methyl-D-galactoside, $\alpha$-methyl-D-glucoside, $\quad \beta$-methyl-D-glucoside, $\alpha$ methyl-D-mannoside, palatinose, D-raffinose, L-rhamnose, D-ribose, salicin, sedoheptulosan, D-sorbitol, stachyose, Dtagatose, xylitol, D-xylose, acetic acid, $\alpha$-hydroxybutyric acid, $\beta$-hydroxybutyric acid, $\gamma$-hydroxybutyric acid, $p$ hydroxyphenylacetic acid, $\alpha$-ketoglutaric acid, $\alpha$-ketovaleric acid, lactamide, D-malic acid, L-malic acid, succinic acid monomethyl ester, propionic acid, pyruvic acid, succinamic acid, succinic acid, $\mathrm{N}$-acetyl-L-glutamic acid, L-alaninamide, D-alanine, L-alanine, L-alanylglycine, L-asparagine, L-glutamic acid, glycyl-L-glutamic acid, L-pyroglutamic acid, putrescine, 2,3-butanediol, adenosine, 2'-deoxyadenosine, inosine, thymidine, uridine, adenosine- $5^{\prime}$-monophosphate, thymidine- $5^{\prime}$-monophosphate, uridine- $5^{\prime}$-monophosphate, D-fructose 6-phosphate, $\alpha$-D-glucose 1-phosphate, $\alpha$-Dglucose 6-phosphate and DL- $\alpha$-glycerol phosphate. Resistant to gentamicin, kanamycin and nalidixic acid; sensitive to ampicillin, chloramphenicol, erythromycin, penicillin G, rifampicin, novobiocin, streptomycin and tetracycline. The peptidoglycan type is $\mathrm{A} 3 \alpha$ containing 
lysine, glutamic acid and alanine. The predominant polar lipids are phosphatidylglycerol and diphosphatidylglycerol, with some unknown phospho- and glycolipids as minor components. Predominant fatty acids are anteiso-15:0, anteiso-17:0 and 16:0. The major menaquinone is MK-7. DNA G + C content is $56.1 \mathrm{~mol} \%$.

The type strain, $\mathrm{L}-143^{\mathrm{T}}\left(=\mathrm{BCRC} 17588^{\mathrm{T}}=\mathrm{LMG} 23708^{\mathrm{T}}\right)$, was isolated from wasteland soil in Tainan County, Taiwan.

\section{Acknowledgements}

W. M. Chen was supported by grants from the National Science Council, Taipei, Taiwan, Republic of China (NSC 95-2320-B-022001-MY2 and 95-2313-B-022-001). We thank F.-S. Wu, Biochemistry Research Facilities, Department of Life Science, National Tsing Hua University, for amino acid analysis.

\section{References}

Chen, W. M., Laevens, S., Lee, T. M., Coenye, T., de Vos, P., Mergeay, M. \& Vandamme, P. (2001). Ralstonia taiwanensis sp. nov., isolated from root nodules of Mimosa species and sputum of a cystic fibrosis patient. Int J Syst Evol Microbiol 51, 1729-1735.

Chun, J., Lee, J. H., Jung, Y., Kim, M., Kim, S., Kim, B. K. \& Lim, Y. W. (2007). EzTaxon: A web-based tool for the identification of prokaryotes based on $16 \mathrm{~S}$ ribosomal RNA gene sequences. Int J Syst Evol Microbiol 57, 2259-2261.

Chung, Y. C., Kobayashi, T., Kanai, H., Akiba, T. \& Kudo, T. (1995). Purification and properties of extracellular amylase from the hyperthermophilic archeon Thermococccus profundus DT5432. Appl Environ Microbiol 61, 1502-1506.

Collins, M. D. (1994). Isoprenoid quinones. In Chemical Methods in Prokaryotic Systematics, pp. 265-309. Edited by M. Goodfellow \& A. G. O’Donnell. Chichester: Wiley.

Collins, M. D., Hutson, R. A., Baverud, V. \& Falsen, E. (2000). Characterization of a Rothia-like organism from a mouse: description of Rothia nasimurium sp. nov. and reclassification of Stomatococcus mucilaginosus as Rothia mucilaginosa comb. nov. Int J Syst Evol Microbiol 50, 1247-1251.

Embley, T. M. \& Wait, R. (1994). Structural lipids of eubacteria. In Chemical Methods in Prokaryotic Systematics, pp. 121-161. Edited by M. Goodfellow \& A. G. O’Donnell. Chichester: Wiley.

Ezaki, T., Hashimoto, Y. \& Yabuuchi, E. (1989). Fluorometric deoxyribonucleic acid-deoxyribonucleic acid hybridization in microdilution wells as an alternative to membrane filter hybridization in which radioisotopes are used to determine genetic relatedness among bacterial strains. Int J Syst Bacteriol 39, 224-229.

Fan, Y., Jin, Z., Tong, J., Li, W., Pasciak, M., Gamian, A., Liu, Z. \& Huang, Y. (2002). Rothia amarae sp. nov., from sludge of a foul water sewer. Int J Syst Evol Microbiol 52, 2257-2260.

Felsenstein, J. (1981). Evolutionary trees from DNA sequences: a maximum likelihood approach. J Mol Evol 17, 368-376.

Georg, L. K. \& Brown, J. M. (1967). Rothia, gen. nov., an aerobic genus of the family Actinomycetaceae. Int J Syst Bacteriol 17, 79-88.

Gerhardt, P., Murray, R. G. E., Wood, W. A. \& Krieg, N. R. (editors) (1994). Methods for General and Molecular Bacteriology. Washington, DC: American Society for Microbiology.

Hall, T. A. (1999). BioEdit: a user-friendly biological sequence alignment editor and analysis program for Windows 95/98/NT. Nucleic Acids Symp Ser 41, 95-98.
Hayakawa, M. \& Nonomura, H. (1987). Humic acid-vitamin agar, a new medium for the selective isolation of soil actinomycetes. J Ferment Technol 65, 501-509.

Jukes, T. H. \& Cantor, C. R. (1969). Evolution of protein molecules. In Mammalian Protein Metabolism, vol. 3, pp. 21-132. Edited by H. N. Munro. New York: Academic Press.

Kluge, A. G. \& Farris, F. S. (1969). Quantitative phyletics and the evolution of anurans. Syst Zool 18, 1-32.

Kumar, S., Tamura, K. \& Nei, M. (2004). MEGA3: integrated software for molecular evolutionary genetics analysis and sequence alignment. Brief Bioinform 5, 150-163.

Lanyi, B. (1987). Classical and rapid identification methods for medically important bacteria. Methods Microbiol 19, 1-67.

Li, Y., Kawamura, Y., Fujiwara, N., Naka, T., Liu, H., Huang, X., Kobayashi, K. \& Ezaki, T. (2004). Rothia aeria sp. nov., Rhodococcus baikonurensis sp. nov. and Arthrobacter russicus sp. nov., isolated from air in the Russian space laboratory Mir. Int J Syst Evol Microbiol 54, 827-835.

MacFaddin, J. F. (2000). Biochemical Tests for the Identification of Medical Bacteria, 3rd edn. Baltimore, MD: Williams \& Wilkins.

Mesbah, M., Premachandran, U. \& Whitman, W. B. (1989). Precise measurement of the $\mathrm{G}+\mathrm{C}$ content of deoxyribonucleic acid by highperformance liquid chromatography. Int J Syst Bacteriol 39, 159-167.

Minato, K. \& Abiko, Y. (1984). $\beta$-Lactam antibiotics resistant Rothia dentocariosa from infected postoperative maxillary cyst: studies on Rplasmid and $\beta$-lactamase. Gen Pharmacol 15, 287-292.

Pape, J., Singer, C., Krehn, T. E., Lee, B. J. \& Armstrong, D. (1979). Infective endocarditis caused by Rothia dentocariosa. Ann Intern Med 91, 746-747.

Pers, C., Kristiansen, J. E., Joensson, V. \& Hansen, N. E. (1987). Rothia dentocariosa septicemia in a patient with chronic lymphocytic leukaemia and toxic granulocytopenia. Dan Med Bull 34, 322-323.

Powers, E. M. (1995). Efficacy of the Ryu nonstaining KOH technique for rapidly determining gram reactions of food-borne and waterborne bacteria and yeasts. Appl Environ Microbiol 61, 3756-3758.

Saitou, N. \& Nei, M. (1987). The neighbor-joining method: a new method for constructing phylogenetic trees. Mol Biol Evol 4, 406-425.

Sasser, M. (1990). Identification of bacteria by gas chromatography of cellular fatty acids, MIDI Technical Note 101. Newark, DE: MIDI Inc.

Schaal, K. P. (1992). The genera Actinomyces, Arcanobacterium, and Rothia. In The Prokaryotes, 2nd edn, pp. 850-905. Edited by A. Balows, H. G. Trüper, M. Dworkin, W. Harder \& K.-H. Schleifer. New York: Springer.

Schafer, F. J., Wing, E. J. \& Norden, C. W. (1979). Infectious endocarditis caused by Rothia dentocariosa. Ann Intern Med 91, 747-748.

Schiff, M. J. \& Kaplan, M. H. (1987). Rothia dentocariosa pneumonia in an immunocompromised patient. Lung 165, 279-282.

Schleifer, K. H. (1985). Analysis of the chemical composition and primary structure of murein. Methods Microbiol 18, 123-156.

Schleifer, K. H. \& Kandler, O. (1972). Peptidoglycan types of bacterial cell walls and their taxonomic implications. Bacteriol Rev 36, 407-477.

Stackebrandt, E., Rainey, F. A. \& Ward-Rainey, N. L. (1997). Proposal for a new hierarchic classification system, Actinobacteria classis nov. Int J Syst Bacteriol 47, 479-491.

Wayne, L. G., Brenner, D. J. \& Colwell, R. R., Grimont, P. A. D., Kandler, O., Krichevsky, M. I., Moore, L. H., Moore, W. E. C., Murray, R. G. E. \& other authors (1987). International Committee on Systematic Bacteriology. Report of the ad hoc committee on reconciliation of approaches to bacterial systematics. Int $J$ Syst Bacteriol 37, 463-464. 